\title{
Quality of Life After a Low Anterior Resection for Rectal Cancer in Elderly Patients
}

\author{
Verena N.N. Kornmann, Marieke S. Walma, Marnix A.J. de Roos ${ }^{1}$, Djamila Boerma, \\ Henderik L. van Westreenen \\ Department of Surgery, St. Antonius Hospital, Nieuwegein; ${ }^{1}$ Department of Surgery, Rivierenland Hospital, Tiel, The Netherlands
}

Purpose: Fecal incontinence is a major concern, and its incidence increases with age. Quality of life may decrease due to fecal incontinence after both sphincter-saving surgery and a rectal resection with a permanent stoma. This study investigated quality of life, with regard to fecal incontinency, in elderly patients after rectal-cancer surgery.

Methods: All patients who underwent elective rectal surgery with anastomosis for rectal cancer between December 2008 and June 2012 at two Dutch hospitals were eligible for inclusion. The Wexner and the fecal incontinence quality of life (FIQoL) scores were collected. Young ( $<70$ years of age) and elderly ( $\geq 70$ years of age) patients were compared.

Results: Seventy-nine patients were included, of whom 19 were elderly patients (24.1\%). All diverting stomas that had been placed $(n=60,75.9 \%)$ had been closed at the time of the study. There were no differences in Wexner or FIQoL scores between the young and the elderly patients. Also, there were no differences between patients without a diverting stoma and patients in whom bowel continuity had been restored. Elderly females had significantly worse scores on the FIQoL subscales of coping/behavior $(\mathrm{P}=0.043)$ and depression/self-perception $(\mathrm{P}=0.004)$ than young females. Elderly females scored worse on coping/behavior $(P=0.010)$ and depression/self-perception $(P=0.036)$ than elderly males. Young and elderly males had comparable scores.

Conclusion: Quality of life with regard to fecal incontinency is worse in elderly females after sphincter-preserving surgery for rectal cancer. Patients should be informed of this impact, and a definite stoma may be considered in this patient group.

Keywords: Rectal cancer surgery; Pelvic floor; Incontinence; Stoma; Quality of life

\section{INTRODUCTION}

With age, the functions of the anal sphincter and the anorectum change [1]. Fecal incontinence is a major concern, especially in the elderly, and may affect up to $65 \%$ of nursing-home residents [2]. Also, as the population ages, the incidence of cancer increases, and more elderly patients will undergo surgery for rectal cancer [3-5]. Although oncological results are equal, rectal surgery with sphincter preservation may be preferred over abdominal perineal

Received: August 12, 2015 - Accepted: December 13, 2015

Correspondence to: Verena N.N. Kornmann, M.D.

Department of Surgery, St. Antonius Hospital, Koekoekslaan 1, 3435 CM

Nieuwegein, The Netherlands

Tel: +31-(0)30-6092052, Fax: +31-(0)30-6036578

E-mail:vnnkornmann@gmail.com

(C) 2016 The Korean Society of Coloproctology

This is an open-access article distributed under the terms of the Creative Commons Attribution NonCommercial License (http://creativecommons.org/licenses/by-nc/4.0) which permits unrestricted noncommercial use, distribution, and reproduction in any medium, provided the original work is properly cited. resections in which a permanent stoma is created because a stoma is thought to seriously limit the patient's quality of life [6]. Nonetheless, the results reported in the literature on better quality of life after either sphincter-saving surgery or abdominal perineal resection are controversial, and a wide spectrum of symptoms due to changes in bowel habit, including fecal incontinence and anorectal dysfunction, have been described [7-10]. Although the overall quality of life of elderly patients seemed to be similar to that of younger patients in a recent review [11], fecal incontinence was a major concern of elderly patients, even those who had not undergone surgery. This raises the question whether sphinctersaving surgery to preserve the sphincter function or a rectal resection with the creation of a permanent stoma should be used for the treatment of elderly patients with rectal cancer. To gain more insight into this topic, we investigated the quality of life, in terms of fecal incontinency, in elderly patients following rectal-cancer surgery and compared the results with those for a younger group of patients. 


\section{METHODS}

All patients who underwent elective rectal surgery with primary anastomosis for rectal cancer at two Dutch hospitals (St. Antonius Hospital, Nieuwegein, The Netherlands, and Rivierenland Hospital, Tiel, The Netherlands) between December 2008 and June 2012 were found to be eligible for inclusion in this study. Inclusion criteria were adult patients with a rectal carcinoma who had undergone a rectal resection, including an anterior and a low anterior resection with primary anastomosis. A rectal tumor was defined using sagittal reconstructions of pelvic magnetic resonance imaging (MRI) (a tumor below an imaginary line from the upper part of the pubic symphysis to the promontory) or sigmoidoscopy (tumor less than $15 \mathrm{~cm}$ from the anal verge). Exclusion criteria were rectal resections for benign disease and other colorectal resections and procedures without anastomosis, including Hartmann's procedure or an abdominoperineal resection.

Surgery was performed according to the total mesorectal excision technique by using either a laparotomy or laparoscopy. High ligation of the inferior mesenteric vasculature and mobilization of the splenic flexure were performed. The rectum was dissected with nerve preservation and reconstructed with a side-to-end stapled colorectal anastomosis. In some cases, a diverting ileostomy was created.

All data, including demographic data, clinical records, oncological and pathology reports and operative reports were collected into a database. The Charlson Comorbidity Index (age unadjusted) and the International Classification of Diseases were used to score comorbidity $[12,13]$. Follow-up for postoperative morbidity or mortality was at least 30 days postoperatively.

In this study, almost all patients with rectal cancer underwent a full preoperative workup, including colonoscopy, pelvis MRI or computed tomography (CT), and thoracic and/or abdominal CT scan. All cases of patients were discussed by a multidisciplinary oncology review board. Following Dutch guidelines for the treatment of colorectal cancer, surgery preceded by irradiation was indicated for all patients with T2-T4 stage tumors. Patients in whom a positive circumferential margin was expected or four or more lymph nodes were suspected as being tumor-positive were preferably treated with chemotherapy (mostly capecitabine 825 $\mathrm{mg} / \mathrm{m}^{2}$ bid) during long-term radiotherapy ( $2 \mathrm{~Gy} \times 25 \mathrm{~Gy}$ ). For all other patients, a short course of radiation therapy was recommended (5 Gy × 5 Gy).

The primary outcome was quality of life associated with incontinence, which was measured using the validated Wexner incontinence score and the fecal incontinence quality of life (FIQoL) scale $[14,15]$. All eligible patients were contacted by one researcher to ask for participation in the study and to obtain informed consent. After permission, a self-administered questionnaire was sent to these patients by email or by letter. Nonresponders were reminded with one extra phone call. All individual aspects of the questionnaires and the total scores were collected.
The Wexner scores ranged from 0 to 20, with a higher score indicating a higher degree of fecal incontinence. The FIQoL scale includes four subscales: lifestyle, coping/behavior, depression/selfperception, and embarrassment, with each subscale's score ranging from 1 to 5 , and the scores for these four subscales were summed to give the total FIQoL score. A lower score indicates a worse quality of life due to incontinence. The median time interval between surgery and the questionnaires was 20 months (interquartile range [IQR], 11-30 months).

Patients were divided into a younger and an elderly patient group, in which elderly were defined as an age of 70 years or older. Data were expressed as numbers of patients (with percentages) or medians with IQRs. Differences between the 2 groups were tested using the Mann-Whitney $U$ test. A P-value less than 0.050 was used as the level of significance. The data were analyzed with IBM SPSS Statistics ver. 19.0 (IBM Co., Armonk, NY, USA).

\section{RESULTS}

\section{Patient and perioperative characteristics}

Rectal resection for rectal cancer was performed in 138 patients during the study period. Fourteen patients who died during follow-up, 27 patients who had a diverting stoma in situ, and another 18 patients who were unresponsiveness, lost to follow up, had incomplete data, or had not given permission for inclusion were excluded. Finally, 79 of the contacted patients were included. The median age was 63 years (IQR, 57-69 years), with 19 elderly patients (24.1\%). There were 53 males $(67.1 \%)$ and 26 females (32.9\%). The median distance of the tumor from the anal verge was $9.0 \mathrm{~cm}$ (IQR, $6.0-12.0 \mathrm{~cm}$ ). Upon pathological examination, $8.9 \%$ of the patients were diagnosed with TNM-stage T1 $(\mathrm{n}=7)$, $43.0 \%$ with T2 ( $\mathrm{n}=34), 45.6 \%$ with T3 $(\mathrm{n}=36)$, and $2.5 \%$ with T4 $(n=2)$. Neoadjuvant therapy was given in most patients and did not significantly differ between the 2 patient groups. A diverting stoma was placed in 60 patients (75.9\%), and at the time of the questionnaire, all stomas were closed. Baseline and operation-related characteristics are summarized in Table 1. Younger and elderly patients differed significantly, with more blood loss and an increased length of stay being observed in the elderly patient group (Table 1).

\section{Wexner and FIQoL scores in the elderly}

The median Wexner and the FIQoL scores are summarized in Table 2. No significant differences in the scores between younger and elderly patients were observed. When the scores for patients who underwent surgery without the creation of a diverting stomy ( $n=19)$ were analyzed, no significant difference in either the Wexner or the FIQoL score between younger $(\mathrm{n}=15)$ and elderly $(\mathrm{n}=4)$ patients was observed. Also, when the scores of patients in whom bowel continuity had been restored after a diverting stoma were analyzed, no significant differences between younger ( $\mathrm{n}=$ $45)$ and elderly $(n=15)$ patients were noted (data not shown). In 
Table 1. Baseline and perioperative characteristics

\begin{tabular}{|c|c|c|c|c|}
\hline Characteristic & All patients $(n=79)$ & Age $<70$ years $(n=60)$ & Age $\geq 70$ years $(n=19)$ & P-value \\
\hline \multicolumn{5}{|l|}{ General parameters } \\
\hline Age at surgery (yr) & $63(57-69)$ & $60(53-65)$ & $72(70-78)$ & $<0.001$ \\
\hline \multicolumn{5}{|l|}{ Sex } \\
\hline Male & $53(67.1)$ & $39(65.0)$ & $14(73.7)$ & 0.673 \\
\hline Female & $26(32.9)$ & $21(35.0)$ & $5(26.3)$ & \\
\hline Body mass index $\left(\mathrm{kg} / \mathrm{m}^{2}\right)$ & $26.4(23.7-28.8)$ & $26.5(23.8-28.7)$ & $26.0(23.5-29.1)$ & 0.991 \\
\hline $\mathrm{CCl}$ & $2(2-3)$ & $2(2-3)$ & $2(2-3)$ & 0.471 \\
\hline Alcohol & $53(67.1)$ & $40(66.7)$ & $13(68.4)$ & 0.887 \\
\hline Smoking & $10(12.7)$ & $6(10.0)$ & $4(21.1)$ & 0.386 \\
\hline Previous abdominal surgery & $22(27.8)$ & $40(66.7)$ & $11(57.9)$ & 0.525 \\
\hline \multicolumn{5}{|l|}{ T-stage (TNM-classification) } \\
\hline $\mathrm{T} 1$ & $7(8.9)$ & $5(8.3)$ & $2(10.5)$ & 1.000 \\
\hline T2 & $34(43.0)$ & $29(48.3)$ & $5(26.3)$ & 0.155 \\
\hline T3 & $36(45.6)$ & $26(43.3)$ & $10(52.6)$ & 0.656 \\
\hline $\mathrm{T} 4$ & $2(2.5)$ & $0(0)$ & $2(10.5)$ & 0.088 \\
\hline Distance of the tumor from anal verge $(\mathrm{cm})$ & $9.0(6.0-12.0)$ & $8.5(6.0-12.0)$ & $10.0(8.0-14.0)$ & 0.089 \\
\hline Neoadjuvant therapy & $61(77.2)$ & $47(78.3)$ & $14(73.7)$ & 0.915 \\
\hline Short-course radiotherapy & $46(58.2)$ & $33(55.0)$ & $13(68.4)$ & 0.443 \\
\hline Chemoradiation & $15(19.0)$ & $14(23.3)$ & $1(5.3)$ & 0.157 \\
\hline \multicolumn{5}{|l|}{ Intraoperative parameters } \\
\hline \multicolumn{5}{|l|}{ Approach } \\
\hline Laparotomy & $11(13.9)$ & $9(15.0)$ & $2(10.5)$ & 0.912 \\
\hline Laparoscopy & $65(82.3)$ & $49(81.7)$ & $16(84.2)$ & 1.000 \\
\hline Conversion & $3(3.8)$ & $2(3.3)$ & $1(5.3)$ & 1.000 \\
\hline \multicolumn{5}{|l|}{ Diverting stomy } \\
\hline lleostomy & $57(72.2)$ & $42(70.0)$ & $15(78.9)$ & 0.642 \\
\hline Colostomy & $3(3.8)$ & $3(5.0)$ & $0(0)$ & 0.760 \\
\hline Duration of surgery (min) & $160(120-240)$ & $160(120-217)$ & $180(130-250)$ & 0.704 \\
\hline Blood loss (mL) & $100(30-350)$ & $100(30-200)$ & $300(100-500)$ & 0.021 \\
\hline \multicolumn{5}{|l|}{ Postoperative parameters } \\
\hline Length of stay at the hospital (day) & $6(5-10)$ & $6(4-10)$ & $8(5-22)$ & 0.022 \\
\hline \multicolumn{5}{|l|}{ Complications } \\
\hline Anastomotic leakage & $5(6.3)$ & $5(8.3)$ & $0(0)$ & 0.448 \\
\hline Stoma-related complications & $9(11.4)$ & $7(11.7)$ & $2(10.5)$ & 1.000 \\
\hline Reoperation/reintervention & $7(8.9)$ & $5(8.3)$ & $2(10.5)$ & 1.000 \\
\hline
\end{tabular}

Values are presented as median (interquartile range) or number of patients (\%).

$\mathrm{CCl}$, Charlson comorbidity index.

elderly patients, a trend to have a worse FIQoL lifestyle and coping/behavior score was seen, although this was not statistically significant (Table 3).

\section{Males versus females}

Figs. 1 and 2 present the result for subanalyses of males $(n=53)$ and females $(\mathrm{n}=26)$. The Wexner and the (subscale) FIQoL scores were comparable for males and females $(\mathrm{P}>0.500$; data not shown). Wexner scores were higher in elderly females compared with elderly males, indicating a worse degree of incontinence, but this was not statistically significant $(P=0.086)$. Statistically significant differences in the scores for coping/behavior ( $\mathrm{P}$ 
Table 2. Wexner and FIQoL scores

\begin{tabular}{lcccc}
\hline Variable & All patients $(n=79)$ & Age $<70$ years $(n=60)$ & Age $\geq 70$ years $(n=19)$ & P-value \\
\hline Wexner score & $7.0(4.0-12.0)$ & $7.0(4.0-11.8)$ & $7.0(4.0-14.0)$ & 0.904 \\
FIQoL score & & & & \\
$\quad$ Lifestyle & $3.5(3.0-4.0)$ & $3.5(3.0-4.0)$ & $3.5(2.3-4.0)$ & 0.831 \\
Coping/behavior & $2.9(2.4-3.7)$ & $2.8(2.4-3.7)$ & $3.2(2.0-3.7)$ & 0.713 \\
Depression/self-perception & $3.9(3.3-4.3)$ & $3.9(3.3-4.3)$ & $3.8(3.2-4.4)$ & 0.908 \\
Embarrassment & $3.5(3.0-4.0)$ & $3.3(3.0-4.0)$ & $3.7(2.9-4.0)$ & 0.876 \\
Total score & $13.4(11.4-15.7)$ & $13.4(11.5-15.6)$ & $14.3(10.7-15.7)$ & 0.804 \\
\hline
\end{tabular}

Values are presented as median (interquartile range).

FIQoL, fecal incontinence quality of life.

Table 3. Wexner and FIQoL scores for patients with age $\geq 70$ years

\begin{tabular}{lcccc}
\hline Variable & All patients $(\mathrm{n}=19)$ & No stomy $(\mathrm{n}=4)$ & Restoration of bowel continuity $(\mathrm{n}=15)$ & P-value \\
\hline Wexner score & $7.0(4.0-14.0)$ & $5.0(1.0-10.5)$ & $8.0(4.0-13.0)$ & \\
FIQoL score & & & & \\
$\quad$ Lifestyle & $3.5(2.3-4.0)$ & $4.0(3.6-4.0)$ & $3.4(2.1-3.9)$ & 0.051 \\
Coping/behavior & $3.2(2.0-3.7)$ & $4.0(2.5-4.0)$ & $3.0(1.9-3.3)$ & 0.061 \\
Depression/self-perception & $3.8(3.2-4.4)$ & $4.0(3.4-4.4)$ & $3.7(2.3-4.4)$ & 0.801 \\
Embarrassment & $3.7(2.9-4.0)$ & $3.8(3.2-4.0)$ & $3.5(2.6-4.0)$ & 0.327 \\
Total score & $14.3(10.7-15.7)$ & $15.8(12.7-16.4)$ & $13.5(8.5-15.5)$ & 0.167 \\
\hline
\end{tabular}

Values are presented as median (interquartile range).

FIQoL, fecal incontinence quality of life.

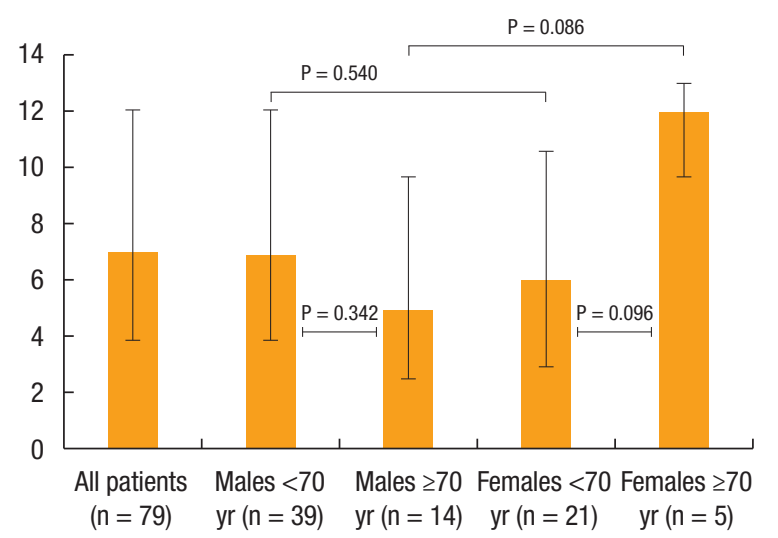

Fig. 1. Wexner scores in male and female patients $<70$ years or $\geq 70$ years of age. A higher score indicates a worse outcome.

$=0.010)$ and depression/self-perception $(\mathrm{P}=0.036)$ were noted, with elderly females having lower (worse) scores compared with elderly males. The other FIQoL subscale scores were comparable between both groups. Elderly females had higher Wexner scores compared with younger females, but this was not statistically significant $(\mathrm{P}=0.096)$. The FIQoL subscale scores for coping/behavior and depression/self-perception were significantly worse in elderly females ( $\mathrm{P}=0.043$ and $\mathrm{P}=0.004$, respectively). Trends showing worse scores on the lifestyle $(\mathrm{P}=0.072)$ and the embarrassment $(\mathrm{P}=0.090)$ subscales were observed. Younger and elderly males had comparable scores. Only younger males scored worse on the FIQoL subscale depression/self-perception compared with younger females $(\mathrm{P}=0.044)$, which is in contrast with elderly males and females.

\section{DISCUSSION}

This study describes the quality of life, in terms of fecal incontinency, in elderly patients after rectal-cancer surgery. Elderly female seemed to have significantly worse scores on two FIQoL subscales (coping/behavior and depression/self-perception) compared with both younger females and elderly males.

First, from the general literature, fecal incontinence is known to occur more frequently in females than in males $[16,17]$. The underlying mechanisms are broad and may include traumatic injuries to the anal sphincter complex and pelvic floor denervation due to vaginal deliveries [17]. Especially, postpartum fecal incontinence is a frequently encountered problem after vaginal delivery and anal sphincter laceration $[18,19]$.

Second, apart from the female gender as a predisposing factor for fecal incontinence, age-related changes in the function of the anal sphincter may play an important role. Several studies showed 


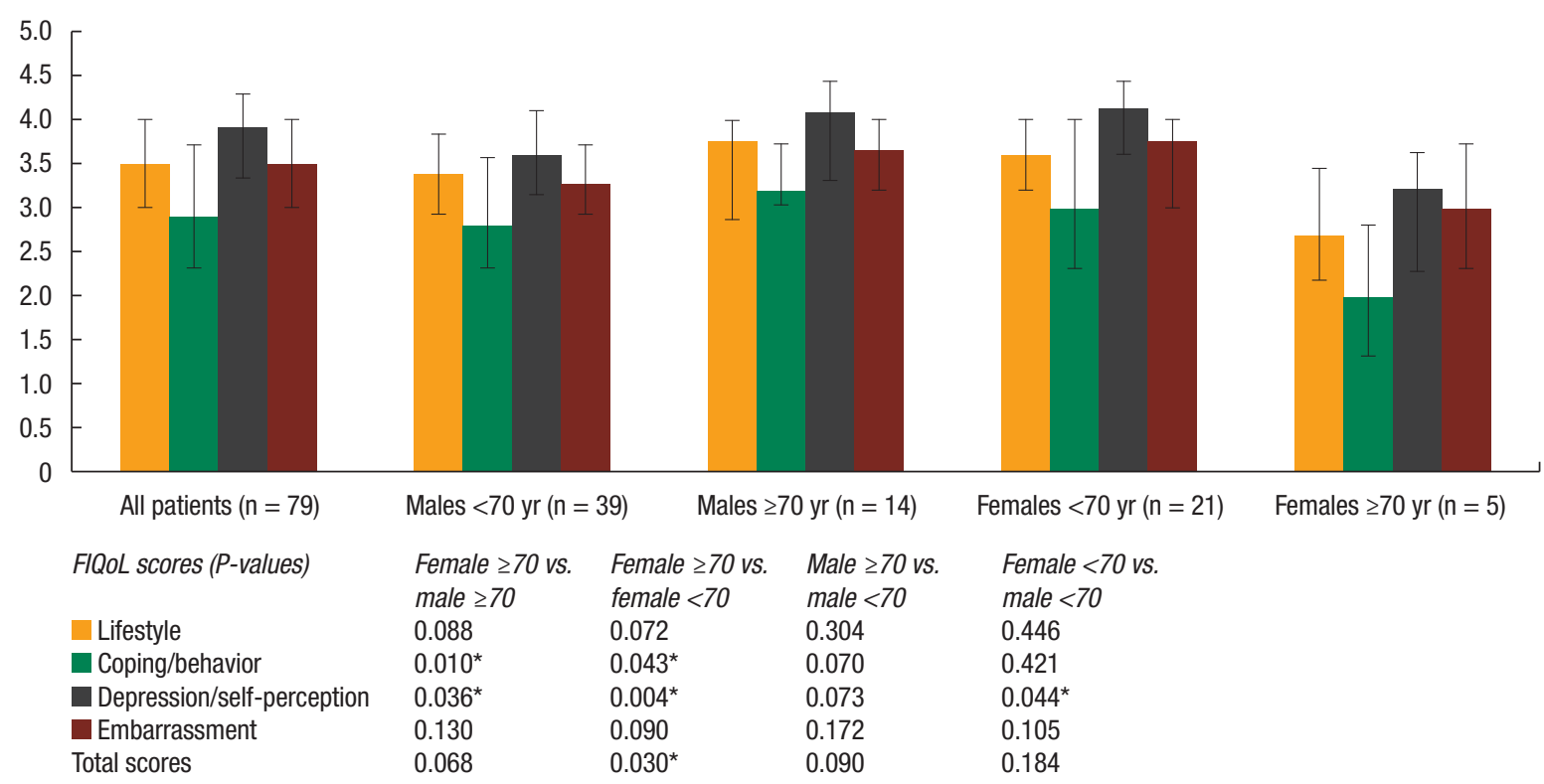

Fig. 2. FIQoL subscale scores in male and female patients $<70$ years or $\geq 70$ years of age with $\mathrm{P}$-values $\left({ }^{\star} \mathrm{P}<0.050\right)$. A lower score indicates a worse outcome. FIQoL, fecal incontinence quality of life.

a thickened external and internal anal sphincter with a decrease in sphincter pressure in the elderly $[1,20]$. Furthermore, elderly females showed a reduced rectal compliance and sensation compared with younger females [2]. The median age of the patients in our group was 63 years. Due to the relatively small patient group, a cutoff point of 70 years was taken to define 'the elderly patient'. Despite this cutoff point, females with an increased age scored significantly worse on the FIQoL subscores.

Finally, iatrogenic anal sphincter damage and the creation of a neorectum (as during rectal-cancer surgery) change the pelvic anatomy, resulting in an altered and diminished anal function with an increased risk of anterior resection syndrome [8]. Also, it has been suggested that neoadjuvant therapy may affect anorectal function, but the literature on that subject is controversial and limited [8].

Treatment modalities for fecal incontinence after rectal surgery primary consist of dietary regimes and constipation agents. Also, colonic irrigation has been described to reduce symptoms and improve quality of life [20]. If these treatments fail, biofeedback training, which includes training of the external sphincter contractility and the physiotherapy of the pelvic floor muscles, may be an alternative [20]. Limited studies have shown improvement in the degree of fecal incontinence after biofeedback training [21]. A more recently-developed treatment is sacral nerve stimulation, in which a permanent pacemaker and electrode are placed to stimulate the sensory, motoric, and autonomic nerves of the sacral roots [22].

The Wexner score did not significantly differ between younger and elderly patients, in contrast to the FIQoL subscale scores. The Wexner score includes questions on the type of incontinence, but not on the quality of life. A few years ago, the low anterior resection syndrome score was developed, which is a score based on the impact of low anterior resection syndrome on the quality of life $[23,24]$.

As different treatment options have been introduced during the last years to improve sphincter function and reduce fecal incontinence, the main question of how to treat the elderly (female) patient still remains. Good cognition, cooperation, mobility and a low comorbidity status are required for a more successful outcome of these treatment options in the reduction of fecal incontinence, but elderly patients are usually not the most optimal patients for most of these treatments. This further raises the question of whether or not to perform sphincter-preserving rectalcancer surgery on elderly patients.

The main limitation of this study was its retrospective character. Questionnaires were completed months after surgery, and no information on the quality of life prior to surgery was available. Patients in whom bowel continuity was not restored at the time of this study were excluded. Also, a large group was excluded due to mortality, loss during follow-up, unresponsiveness, or no permission for inclusion, which may have introduced selection bias. Furthermore, the obstetric history of the females was missing in the database. However, despite this small group of patients, significant differences were seen between patient groups. Large observational cohort studies are necessary to identify risk factors and to determine the role of endoscopic ultrasound or physiotherapy.

In conclusion, elderly females have a decreased quality of life in terms of coping/behavior and depression/self-perception due to fecal incontinency following rectal-cancer surgery. The elderly female patient (taking the obstetric history into account) should 
specifically be informed about the impact related to quality of life and the risk of anterior resection syndrome, and these should not be underestimated by clinicians or patients. The creation of a definite stoma or not restoring bowel continuity should, therefore, be strongly considered in this patient group.

\section{CONFLICT OF INTEREST}

No potential conflict of interest relevant to this article was reported.

\section{REFERENCES}

1. Yu SW, Rao SS. Anorectal physiology and pathophysiology in the elderly. Clin Geriatr Med 2014;30:95-106.

2. Shah BJ, Chokhavatia S, Rose S. Fecal incontinence in the elderly: FAQ. Am J Gastroenterol 2012;107:1635-46.

3. Etzioni DA, Beart RW Jr, Madoff RD, Ault GT. Impact of the aging population on the demand for colorectal procedures. Dis Colon Rectum 2009;52:583-90.

4. Jemal A, Siegel R, Ward E, Hao Y, Xu J, Murray T, et al. Cancer statistics, 2008. CA Cancer J Clin 2008;58:71-96.

5. Surgery for colorectal cancer in elderly patients: a systematic review. Colorectal Cancer Collaborative Group. Lancet 2000;356: 968-74.

6. Di Betta E, D’Hoore A, Filez L, Penninckx F. Sphincter saving rectum resection is the standard procedure for low rectal cancer. Int J Colorectal Dis 2003;18:463-9.

7. Williamson ME, Lewis WG, Holdsworth PJ, Finan PJ, Johnston D. Decrease in the anorectal pressure gradient after low anterior resection of the rectum: a study using continuous ambulatory manometry. Dis Colon Rectum 1994;37:1228-31.

8. Bryant CL, Lunniss PJ, Knowles CH, Thaha MA, Chan CL. Anterior resection syndrome. Lancet Oncol 2012;13:e403-8.

9. Cornish JA, Tilney HS, Heriot AG, Lavery IC, Fazio VW, Tekkis PP. A meta-analysis of quality of life for abdominoperineal excision of rectum versus anterior resection for rectal cancer. Ann Surg Oncol 2007;14:2056-68.

10. Pachler J, Wille-Jorgensen P. Quality of life after rectal resection for cancer, with or without permanent colostomy. Cochrane Database Syst Rev 2005;(2):CD004323.

11. Manceau G, Karoui M, Werner A, Mortensen NJ, Hannoun L. Comparative outcomes of rectal cancer surgery between elderly and non-elderly patients: a systematic review. Lancet Oncol 2012; 13:e525-36.

12. Charlson ME, Pompei P, Ales KL, MacKenzie CR. A new method of classifying prognostic comorbidity in longitudinal studies: development and validation. J Chronic Dis 1987;40:373-83.

13. Sundararajan V, Henderson T, Perry C, Muggivan A, Quan H, Ghali WA. New ICD-10 version of the Charlson comorbidity index predicted in-hospital mortality. J Clin Epidemiol 2004;57: 1288-94.

14. Rockwood TH, Church JM, Fleshman JW, Kane RL, Mavrantonis C, Thorson AG, et al. Fecal Incontinence Quality of Life Scale: quality of life instrument for patients with fecal incontinence. Dis Colon Rectum 2000;43:9-16.

15. Vaizey CJ, Carapeti E, Cahill JA, Kamm MA. Prospective comparison of faecal incontinence grading systems. Gut 1999;44:7780.

16. Johanson JF, Lafferty J. Epidemiology of fecal incontinence: the silent affliction. Am J Gastroenterol 1996;91:33-6.

17. Andromanakos N, Filippou D, Skandalakis P, Papadopoulos V, Rizos S, Simopoulos K. Anorectal incontinence. pathogenesis and choice of treatment. J Gastrointestin Liver Dis 2006;15:41-9.

18. Chin K. Obstetrics and fecal incontinence. Clin Colon Rectal Surg 2014;27:110-2.

19. Malek-mellouli M, Assen S, Ben Amara F, Gada H, Masmoudi K, Reziga $\mathrm{H}$. Incidence and risk factors of postpartum anal incontinence: a prospective study of 503 cases. Tunis Med 2014;92:15963.

20. Lundby L, Duelund-Jakobsen J. Management of fecal incontinence after treatment for rectal cancer. Curr Opin Support Palliat Care 2011;5:60-4.

21. Visser WS, Te Riele WW, Boerma D, van Ramshorst B, van Westreenen HL. Pelvic floor rehabilitation to improve functional outcome after a low anterior resection: a systematic review. Ann Coloproctol 2014;30:109-14.

22. Boyle DJ, Murphy J, Gooneratne ML, Grimmer K, Allison ME, Chan CL, et al. Efficacy of sacral nerve stimulation for the treatment of fecal incontinence. Dis Colon Rectum 2011;54:1271-8.

23. Emmertsen KJ, Laurberg S. Low anterior resection syndrome score: development and validation of a symptom-based scoring system for bowel dysfunction after low anterior resection for rectal cancer. Ann Surg 2012;255:922-8.

24. Juul T, Ahlberg M, Biondo S, Emmertsen KJ, Espin E, Jimenez $\mathrm{LM}$, et al. International validation of the low anterior resection syndrome score. Ann Surg 2014;259:728-34. 